\title{
Travel Patterns and Preferences of Urban University Students
}

\author{
By Virginia Sisiopiku*
}

Students at urban university campuses often have distinct travel patterns than other commuters. Few studies have documented university students' travel behavior explicitly, and thus their travel choices and preferences are not well known. Understanding travel patterns and transportation user choices is important for serving student transportation needs within and around university campuses and promoting active and shared transportation mode choices. The objective of this study was to document commuting patterns of students at the University of Alabama at Birmingham (UAB) in order to benchmark current practices and preferences and identify opportunities and barriers to sustainable transportation options in and around the UAB campus. This paper summarizes results from a comprehensive campus-wide anonymous questionnaire survey through which UAB students reported information on their daily travelling habits as they relate to commuting travel modes, origins and destinations, and travel preferences. Analysis of over 4,150 questionnaire responses revealed that UAB students are currently heavily automobile-dependent on their commute to campus with over $82 \%$ of students reporting commuting solo by automobile. Students reported that they shy away from active transportation options because travel times are too long as the majority live outside the limits of comfortable biking or walking. Cross tabulation of responses indicated that the percentage of students walking reduces steadily as they approach graduation (from 23\% in freshman year to $9 \%$ in senior year). Of those choosing active modes, women outnumber male walkers while males show a stronger preference in bicycle use when compared to female students. Students also reported being receptive of the idea of shifting to alternative transportation modes given availability, convenience, and potential incentives. This study can serve as a reference for other university campuses that are interested in understanding commuting patterns of their users in order to reduce single occupancy vehicle use and serve better their current and future commuting needs.

Keywords: Student Commuting Travel Patterns, Travel Surveys, Urban University Campus Transportation.

\section{Introduction}

The University of Alabama at Birmingham (UAB) is Alabama's largest single employer. Located just south of Birmingham's business district, UAB expands over 100 city blocks. The University has grown substantially over the past ten years, both in land use and economic impact. UAB currently hosts more than 19,500 students, and that number is expected to grow to 25,000 by 2020 . The existing six residence halls located on campus house approximately 2,880 students with a student-housing occupancy of $100 \%$ percent.

\footnotetext{
${ }^{*}$ Associate Professor, University of Alabama at Birmingham, USA.
} 
The continuing growth of $\mathrm{UAB}$ and the projected increase in student population in the future are expected to lead to an increased demand for transportation services in and around the UAB campus. Thus it becomes important to ensure that necessary actions are taken to avoid increase in congestion around the university's campus and downtown Birmingham and ensure that commuting needs to/from UAB are met. Good understanding of student commuting patterns and user preferences will help University administrators to make well-informed decisions regarding land use, transportation system improvements, and promotion of alternative transportation options in order to provide a balance between supply and demand and serve accessibility and mobility needs of the UAB community.

Until recently, no data were gathered to document commuting patterns specific to UAB's campus. There was also no known data available regarding student travel preferences or opinions on non-motorized and alternative mode choices. Therefore, a need was identified to gather and analyze commuting data for the UAB campus and gather knowledge about transportation users' opinions and preferences related to commuting to/from the UAB campus.

This study serves to fulfill that need; through the method of anonymous questionnaire surveys, UAB students reported information on their daily travelling habits as they relate to travel modes they use to commute to campus, their origins and destinations, and travel preferences. Such information provides baseline data for analysis and study, upon which future studies can be conducted. The data gathered can be used to benchmark current practices and preferences and help the University and local transportation agencies to better plan for transportation needs of the UAB community in the future.

\section{Background}

University students often have travel patterns that are distinct from other members of a city's population, potentially due to densified living situations (Wang et al., 2012). In literature, a university has been considered a special trip generator and, thus, the standard four-step method of determining trip generation may not deliver accurate results, as it does not take into account individual travel behavior, but rather assumes uniform travel behavior among the same analysis zone. In a university setting, where there are many subpopulations, travel behavior cannot truly be considered uniform. The university students, in particular, are often more physically active than the normal population and are statistically more likely to choose an alternative mode of transportation, such as walking or biking (Ma, 2015). Because of discrete differences in commuting choices, it is important to represent this subpopulation in the surrounding city's transportation models. However, this type of model is neither well studied nor documented in peer-reviewed literature.

Review of the literature reveals that very few studies, even within the National Household Travel Survey (NHTS), have documented university students travel behavior explicitly, and such travel patterns are still not very well 
understood (Wang et al., 2012). Even though NHTS methods for conducting travel demand analysis are widely replicated, they do not specifically cater to university settings, and thus there is a need to alter some of the commonly used methods to fit the specific demographics and adopt to the university environment.

Several examples of studies done to understand university students' travel involve travel diaries (Eom et al., 2009) and student surveys (Ma, 2015). For example, a study at Old Dominion University in Virginia used an adjusted conventional trip diary and found that proximity of residence to campus strongly affected travel mode choice (Wang et al., 2012). Uniquely, the study also reported that there was no strong correlation data between income and travel behavior, which is unlike the case of the typical travel demand model.

Several studies collected and analyzed data using questionnaire surveys. For example, a 2011 survey performed by Ohio State University (OSU) in Columbus Ohio studied travel patterns of the campus community. Respondents were asked questions about their travel modes, attitudes toward vehicle use, and factors affecting their choices. Of the 80,000 that attended and worked at OSU, 2,300 provided responses. About $91 \%$ of respondents had access to a vehicle with $64 \%$ of the off-campus residents reporting driving alone. The study confirmed that the percentage of single occupancy vehicle (SOV) trips increased with distance from campus. More than $75 \%$ of the respondents said they are completely dependent on car use, however, $68 \%$ reported that they were actively trying to reduce their car use and $40 \%$ considered to participate in a carpool. The study concluded that the mode choice of single occupancy drivers was driven by considerations related to travel time, safety, departure time flexibility, and the ability to make stops during the trip (Barata et al., 2011).

The literature review revealed that the limited campus studies analyzing commuting patterns and preferences of university students available in the literature are individualized for specific universities. Such studies can serve as are valuable resources for follow up studies, however, results cannot be directly transferred to other university settings due to important differences related to campus geographic location and size, student population make up, transit availability, and local culture. Therefore, a need to collect student commuting data at UAB was identified in order to (a) better understand the university's unique transportation needs and (b) take actions to address such needs in an effective and sustainable manner both in the near term and long-term future.

\section{Methodology}

After consideration of best practices, it was decided that the best way to collect data that represent a wide range of UAB students' perspectives would be through a voluntary questionnaire survey. Not only does a survey provide respondents with the opportunity to answer specific questions regarding their commutes, but it also provides a platform to gather student opinions in a freeform manner. 
Thus, a questionnaire survey tool was designed based on practices recommended by the Manual of Transportation Engineering Studies (Schroeder et al., 2010) and contained 22 questions. The survey asked participants both qualitative and quantitative questions focusing on:

a) demographic characteristics (age, gender, vehicle ownership, etc.);

b) commuting characteristics (trip origin, home-to-school distance, commuting travel time, commute time of the day, etc.); and

c) commuting mode preferences (drive alone, ride share, bicycle, etc.).

Open-ended questions were also included, allowing students to respond freely to certain questions.

The Survey Monkey internet-based platform was used for developing and administering the questionnaire survey. A mass-email was sent to every student in the UAB BlazerNET system database requesting participation in November 2015. The bulk of the responses were obtained within the two weeks following the launch of the survey.

During the posting time, 4,150 total responses of UAB students were recorded. From the data collected, $68 \%$ of the student respondents were female, and $32 \%$ were male. Over $60 \%$ of student respondents were in the age bracket of 18 to 24 , and $25.3 \%$ were between 25 and 34 years of age. Summary findings from the analysis of the questionnaire responses are summarized next.

\section{Results and Discussion}

\section{Commute Patterns, Time, and Distance}

Knowledge of trip origins is important for understanding travel patterns in the region and developing strategies to improve users' commutes. To identify commuters' trip origins, each respondent had the option to fill in his/her street address and ZIP code.

UAB students responding to the commuter survey reach UAB from 216 ZIP codes. When sorted by frequency, 8 ZIP codes (namely 35205, 35209, $35226,35242,35216,35244,35211$, and 35233) account for over half of the UAB student trip origins. Figure 1 illustrates the UAB students' trips origins distribution by ZIP code area in five aggregated categories that were generated using Jenks natural breaks classification. The data provide useful information about communities that generate commuting travel to UAB and their proximity to the campus. 
Figure 1. Student Trip Origins

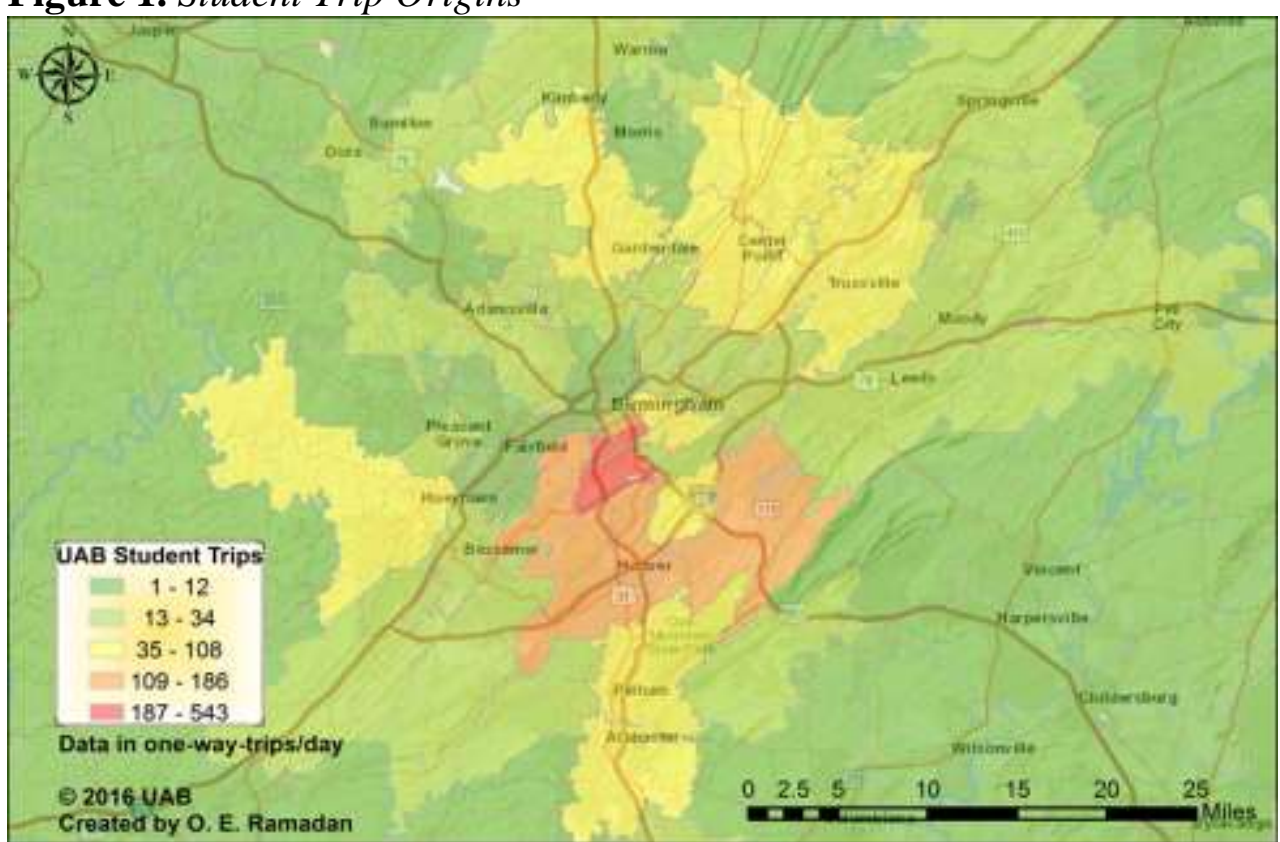

In addition, students were asked to report distance traveled during their home-to-school commute. Approximately $15 \%$ of UAB students responding to the survey reported traveling only 1 mile or less, $22 \%$ reported traveling 1-5 miles to get to the UAB campus while $20 \%$ reported commuting over 21 miles one-way. Survey participants were also asked to report their average commute time (one-way) to campus, the results of which are shown in Figure 2. Comparisons between reported distance traveled and commuting travel times showed that student responses were fairly consistent and accurate, thus increasing the confidence on the validity of the study findings.

Figure 2. Student Commute Time to UAB

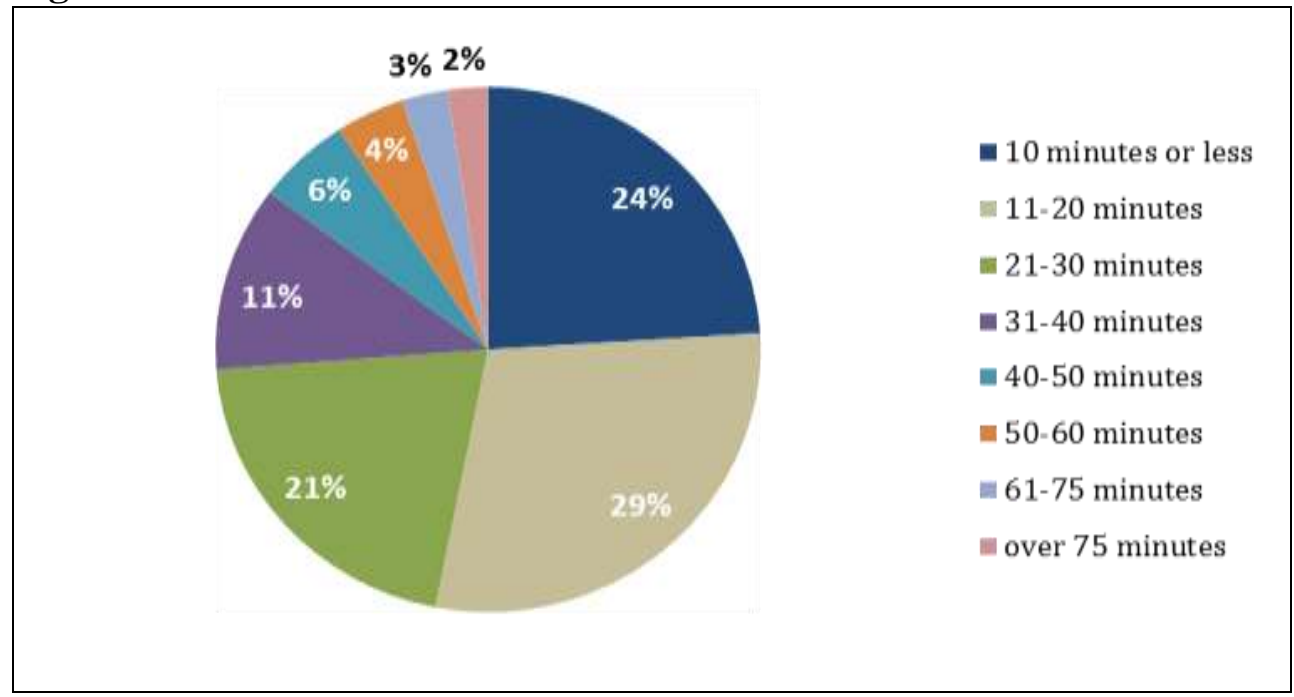




\section{Mode Choice and Influencing Factors}

Figure 3 summarizes students' current mode choices. The data indicate that $82.5 \%$ of UAB students drive alone to/from campus, $11.8 \%$ share rides or use transit, $14.2 \%$ walk, and $3.4 \%$ ride a bike. The responses show that the overwhelming majority of UAB students drive alone to school and confirms the UAB commuters still largely embrace the automobile-dependent commuting culture.

Figure 3. UAB Student Mode Choice

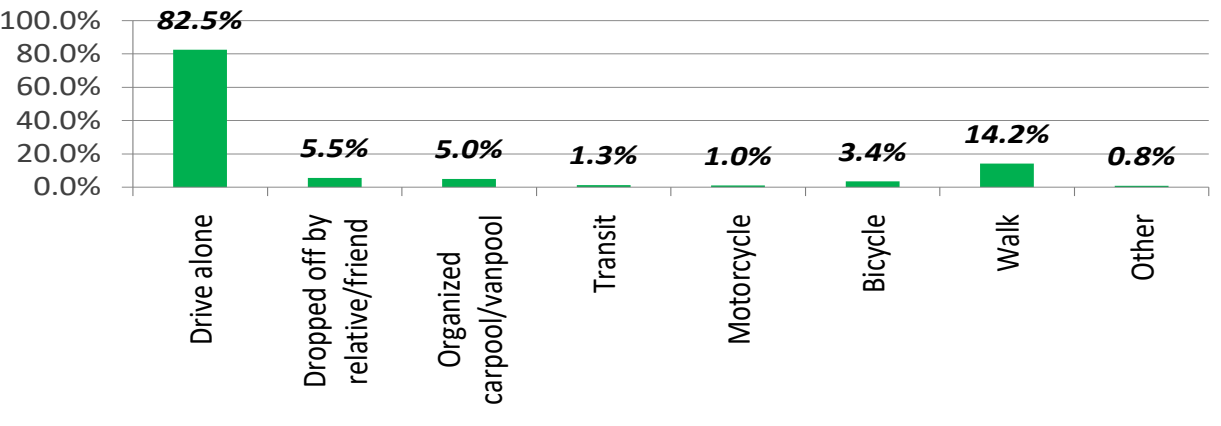

Part of the purpose of the UAB student commuter survey was to understand student opinions on alternative modes of transportation (such as ride sharing, transit, walking, bicycling, etc.). Students were asked to identify the types of transportation modes they would choose if that option was easily available to them. More than one choice was allowed for this question and the responses from this question were summarized in Figure 4.

Figure 4. Student Preferred Mode Choice

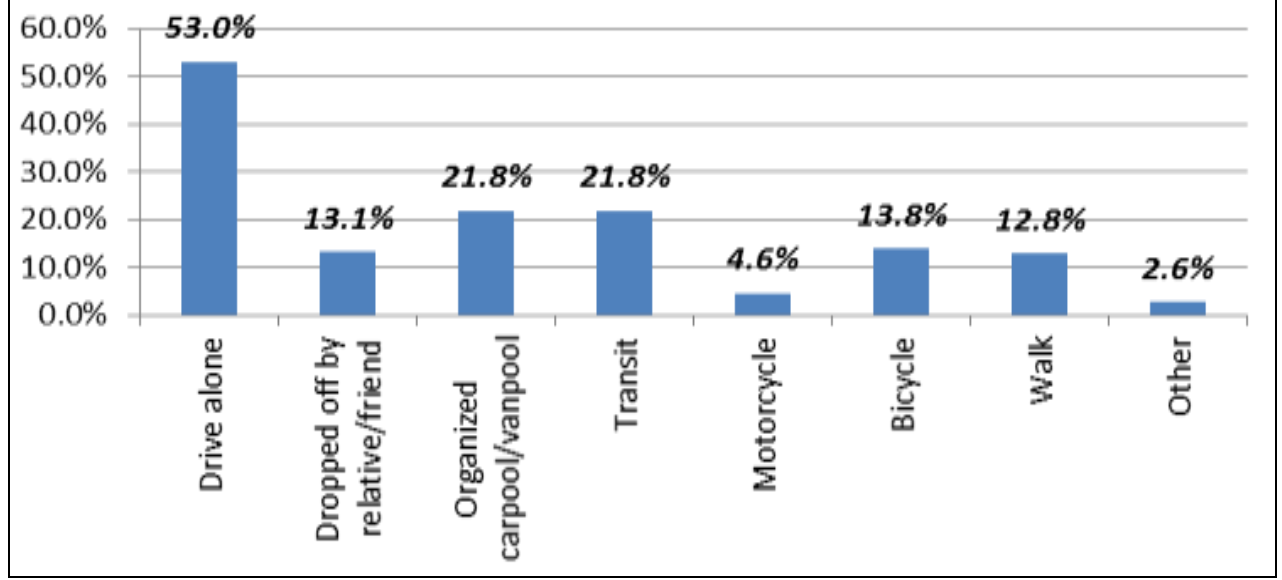


It can be seen that $53 \%$ of respondents would still prefer to drive alone if other mode choices were available, however, the number of survey participants who would consider alternative modes of transportation increased. As indicated in Figure 4, 21\% of students would prefer to take organized carpools/vanpools or transit, while less than 5\% currently use either option. More students would also prefer to bike for their commute than currently do (from $3.4 \%$ who currently use this mode to almost $14 \%$ ), should that option was easily available to them.

Students were also asked to rate specific factors that influenced their mode choice on a scale of 1 to 5 , with 5 being most important and 1 being least important. Highest ranked factors were reliability (4.58) and travel time (4.58), followed by convenience (4.49), and safety (4.42). Considerations related to travel cost and environmental impacts ranked lower to other contributing factors (scoring 3.98 and 3.32 respectively).

Moreover, participants who self-identified as "rarely use carpool" or other alternative transportation modes (specifically transit, biking, and walking) were asked about the reason(s) behind their choice. Figure 5 summarizes these responses by mode and shows that the main reported reason for not choosing carpool/transit, and non-motorized modes were unavailability, and excessive travel time, respectively.

To get feedback from students about possible transportation system improvements, UAB student survey participants were asked to select one or more option from a set of possible transportation improvements. The majority of the student respondents $(91.5 \%)$ stated that there should be more parking spaces on campus; while $29.7 \%$ of the respondents revealed their desire for construction of pedestrians and green spaces. Furthermore, 20.4\% of the respondents reported a need for improvement/expansion of bus service availability.

Figure 5. Student Non-alternative Mode Choice Reasoning

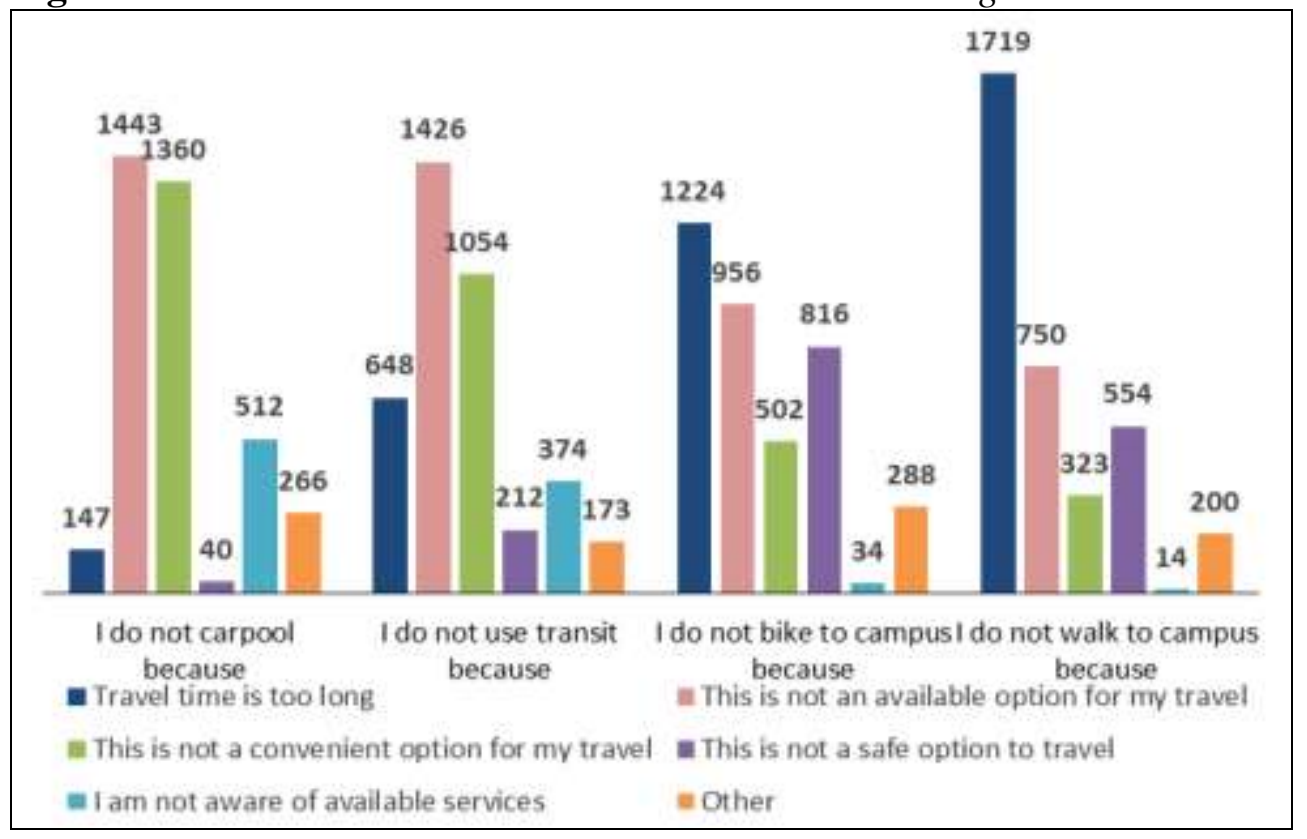




\section{Cross Tabular Analysis}

Cross tabulations between various responses have been used to better understand how some of the study factors affect one another. Table 1 specifically targets student survey responses for further study. The table indicates that freshmen are more likely to walk than other university classifications. The percentages of students who reported that they drive alone are similar across all university classifications, as are the other alternative modes of transportation. Out of all classifications considered, more professional students reported using organized carpool/vanpool for commuting.

Table 1. Student Classification and Mode Choice

\begin{tabular}{|c|c|c|c|c|c|c|c|c|c|}
\hline Class & 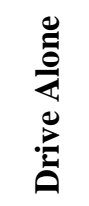 & 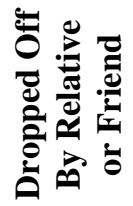 & 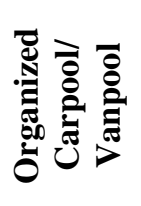 & 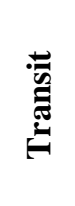 & 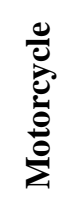 & 苞 & 兰 & 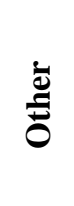 & 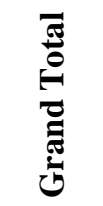 \\
\hline Freshman & $65 \%$ & $5 \%$ & $3 \%$ & $1 \%$ & $0 \%$ & $1 \%$ & $23 \%$ & $0 \%$ & $100 \%$ \\
\hline Sophomore & $68 \%$ & $5 \%$ & $4 \%$ & $1 \%$ & $1 \%$ & $2 \%$ & $18 \%$ & $1 \%$ & $100 \%$ \\
\hline Junior & $77 \%$ & $4 \%$ & $4 \%$ & $1 \%$ & $1 \%$ & $3 \%$ & $10 \%$ & $1 \%$ & $100 \%$ \\
\hline Senior & $77 \%$ & $5 \%$ & $4 \%$ & $1 \%$ & $1 \%$ & $2 \%$ & $9 \%$ & $1 \%$ & $100 \%$ \\
\hline Graduate & $71 \%$ & $5 \%$ & $5 \%$ & $1 \%$ & $1 \%$ & $4 \%$ & $12 \%$ & $1 \%$ & $100 \%$ \\
\hline Professional & $72 \%$ & $5 \%$ & $6 \%$ & $0 \%$ & $2 \%$ & $5 \%$ & $10 \%$ & $0 \%$ & $100 \%$ \\
\hline
\end{tabular}

Table 2 compares mode choice by gender. Keeping in mind that $68 \%$ of respondents were female, and $32 \%$ were male, results shown in this table indicate that females are more likely to use motorized transportation modes than males. It can be also seen that males use two-wheel modes significantly more compared to female students. The results indicate the need for a more indepth study to understand the reasons behind these gender differences in mode choices.

Table 2. Student Gender and Mode Choice

\begin{tabular}{|c|c|c|c|c|c|c|c|}
\hline Gender & 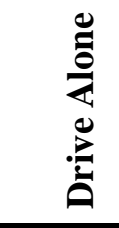 & 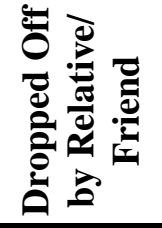 & 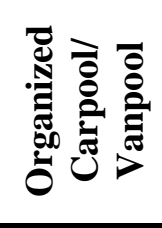 & 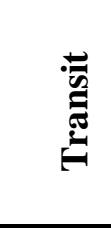 & 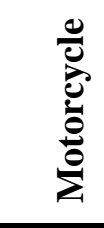 & 苞 & $\stackrel{\bar{F}}{\bar{F}}$ \\
\hline Female & $69 \%$ & $78 \%$ & $74 \%$ & $63 \%$ & $28 \%$ & $45 \%$ & $65 \%$ \\
\hline Male & $31 \%$ & $22 \%$ & $26 \%$ & $37 \%$ & $73 \%$ & $55 \%$ & $35 \%$ \\
\hline Total & $100 \%$ & $100 \%$ & $100 \%$ & $100 \%$ & $100 \%$ & $100 \%$ & $100 \%$ \\
\hline
\end{tabular}

Table 3 shows the impact of commuting distance on mode choice of UAB students. As expected, the vast majority of students walkers and cyclists live on or adjacent to campus, while students commuting more than 5 miles rely heavily on motorized modes for their commutes. 
Table 3. Student Commuting Distance and Mode Choice

\begin{tabular}{|c|c|c|c|c|c|c|c|}
\hline Class & 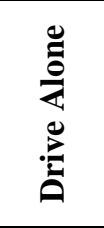 & 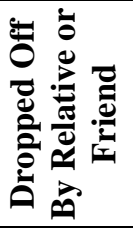 & 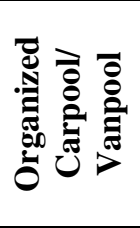 & 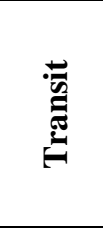 & 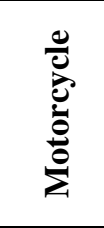 & 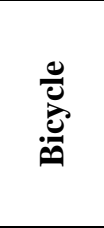 & 兰 \\
\hline$>1$ mile & $6 \%$ & $19 \%$ & $8 \%$ & $35 \%$ & $9 \%$ & $59 \%$ & $84 \%$ \\
\hline 1-5 miles & $22 \%$ & $20 \%$ & $23 \%$ & $54 \%$ & $45 \%$ & $40 \%$ & $14 \%$ \\
\hline 6-10 miles & $21 \%$ & $21 \%$ & $21 \%$ & $12 \%$ & $27 \%$ & $0 \%$ & $1 \%$ \\
\hline 11-15 miles & $16 \%$ & $18 \%$ & $10 \%$ & $0 \%$ & $9 \%$ & $1 \%$ & $1 \%$ \\
\hline 16-20 miles & $13 \%$ & $5 \%$ & $5 \%$ & $0 \%$ & $0 \%$ & $0 \%$ & $0 \%$ \\
\hline 21 miles + & $22 \%$ & $17 \%$ & $33 \%$ & $0 \%$ & $9 \%$ & $0 \%$ & $0 \%$ \\
\hline Total & $100 \%$ & $100 \%$ & $100 \%$ & $100 \%$ & $100 \%$ & $100 \%$ & $100 \%$ \\
\hline
\end{tabular}

It is also worth noting that one third of those that commute by organized carpool reside over 21 miles away from campus. These findings can be very helpful when targeting student sub-populations with customized marketing plans and incentives in order to encourage students to switch to shared or nonmotorized commuting modes. For example, one can identify students interested in ridesharing and use factors like residential proximity and the departures time from the same neighborhood for ride matching purposes.

\section{Open-Ended Response Summary}

The UAB student commuter survey allowed respondents to provide comments or ideas for improving transportation to and from UAB as well as on campus. A total of 2,095 (51\%) respondents provided comments and/or suggestions. Parking issues were the pivot topic for most responses totaling 1,369 comments and representing nearly $65 \%$ of the total comments provided. The most repeated comments were about parking availability for commuter students, and the need for relocating and optimizing parking lots/decks for classes' proximity, as most students cannot find parking near those buildings where they attend classes.

Blazer Express, UAB's campus shuttle bus service, also received attention from students with 143 (7\%) comments. Most comments suggested increasing routes, route optimization, more frequent schedules, and weekend service availability. Additionally, $131(6 \%)$ comments were received about bike facilities. Students suggested installing dedicated bike lanes across campus, and more secure (theft-proof) bike corrals. Also, students suggested optimizing the locations of bike corrals and bike-share facilities with respect to educational buildings and bus stops. Furthermore, 75 (4\%) comments were received regarding transit options and making off-campus areas more accessible to students living on campus. Finally, $48(2 \%)$ student respondents offered comments related to pedestrian facilities and amenities. Some students suggested the realignment of crosswalks and reprogramming of traffic signals to allow dedicated pedestrian phases with adequate walk time. 


\section{Conclusions and Recommendations}

Analysis of nearly 4,150 questionnaire responses revealed that UAB students are currently heavily automobile-dependent for their commute to UAB with over $82 \%$ of them reporting commuting alone to $\mathrm{UAB}$ on their private vehicle. Students reported that the most important factors they consider when choosing a mode are reliability, travel time, and convenience.

Even though the overwhelming majority of students drive alone to UAB currently, UAB student commuters appear receptive of the idea of shifting to more sustainable transportation modes such as carpools, vanpools, and transit, given availability, convenience, and potential incentives. In fact, while only a $5 \%$ percentage of UAB students are currently involved in organized ridesharing, approximately $21 \%$ of student drivers expressed an interest to consider ridesharing alternatives. Moreover, $13 \%$ of students are willing to consider sharing a ride to the UAB campus with a relative or friend while only $5.5 \%$ do so currently. Based on these findings it is recommended that UAB and CommuteSmart (a local rideshare program) work together and target these populations with marketing plans and incentives to encourage mode switching to shared modes.

Under current conditions, most students (94\%) do not use the Blazer Express shuttle bus to move around campus. This could be because the users are not aware of benefits of using the service and/or the buses routes and schedules do not properly serve user needs. It is recommended that this issue is further investigated and necessary actions are taken to increase Blazer Express ridership and optimize routes in response to user needs. Infrastructure improvements to support alternative transportation options on and around campus, such as sidewalks, bicycle lanes, transit stop shelters etc. are also essential.

Deducing from the questionnaire responses of the UAB students it can be concluded that the university should implement a comprehensive parking management strategy that focuses both on the parking supply and parking demand sides in order to address current and future parking needs of the UAB commuters. Such an approach will address current concerns and future needs for parking while maintaining a more sustainable and livable university environment for all. Furthermore, and in response to the results from the rest of the study, a recommendation is offered to incentivize UAB commuters to switch modes by marketing the convenience of not having to find parking on campus when alternative transit modes were chosen. Such recommendations are in line with operational- and policy-driven drive-alone trip reduction strategies recommended in the literature and summarized in Massachusetts Rideshare Program, 2014. Selected strategies that can be adopted by UAB to reduce the number of students driving solo to campus and to promote shared and non-motorized transportation alternatives are summarized in Table 4. 
Table 4. UAB Student Automobile Trip Reduction Incentives

\begin{tabular}{ll}
\hline $\begin{array}{l}\text { Student Auto Trip } \\
\text { Reduction Incentives }\end{array}$ & Description \\
\hline
\end{tabular}

\begin{tabular}{ll}
\hline & $\begin{array}{l}\text { Financial Mechanism. This incentive involves providing a full or } \\
\text { partial subsidy to student commuters that carpool, vanpool, use }\end{array}$ \\
public transportation, walk, or bike. The University may \\
implement a short-term cash-for-transit program, cash-for-gas \\
program for carpoolers, a commuting expense allowance for \\
bicyclists, or other cash incentive program. \\
Connecting/Support Transportation. This incentive involves \\
providing transportation, usually by a van, to connect student \\
commuters from public transportation or park-and-ride lots to \\
campus. The University may also offer a shuttle during the day to \\
connect commuters to nearby town centers or shopping areas.
\end{tabular}

Lockers, changing rooms \& Bicycle Incentive. This incentive involves providing lockers, showers private changing areas, and showers for bicyclists.

Bicycle Incentive. This incentive involves providing bicycle lanes or bike paths on or around the campus for commuter use. Bicycle

On-site bike lane \& path lanes are located in roadways used by vehicles and are clearly demarcated for use by bicycles. Bicycle paths are built exclusively for bicycles and are separate from the flow of vehicles.

Borrow-a-bike

Bicycle Incentive. This incentive involves providing bicycles for student commuters to borrow for the commute to school or for travel during the day.

Parking Control Measure. This incentive involves establishing parking fees and then offering student commuters the equivalent value of that parking when they choose to not park at the facility.

Parking cash-out Students can then purchase a parking space or use the money to buy a transit pass or carpool. Commuters save money because the alternatives to parking are generally less expensive than the parking fees.

Shared Vehicle Services. This incentive involves arranging for the availability of vehicles for students use through a car-sharing

Car-sharing programs program. Car-sharing vehicles are available at convenient locations and students can reserve these vehicles as needed on an hourly basis.

Commuter transportation Administrative Coordination. This incentive involves designating a coordinator full or part-time coordinator for transportation planning activities and compliance with the Rideshare Program at the facility.

Bicycle Incentive. This incentive involves designating a coordinator Bicycle coordinator to organize bicycle events and coordinate bicycle programs to promote bicycling to campus.

Note: Developed based on Input from Massachusetts Rideshare Program, 2014.

It is further recommended that UAB work closely with the Regional Planning Commission of Greater Birmingham, the City of Birmingham, the Alabama Department of Transportation (ALDOT) and other stakeholders to provide alternative transportation options to UAB commuters that are environmental friendly and more sustainable than the use of private automobiles. 
Infrastructure improvements to support such options such as sidewalks, bicycle lanes, transit stop shelters etc. are essential. Campaigns to educate student commuters about the benefits of using sustainable commute options as well as incentives to encourage them to switch to active or ride sharing modes and reduce the use of automobile within and around the UAB campus are needed and highly recommended.

Evidence from other campuses exists that initiatives promoting the use of shared and active transportation modes can reduce the number of solo commuters to campus. For example, after Portland State University's (PSU) introduced various active transportation initiatives such as providing bike trails, dedicated bike lanes and amenities of bicycle users, it managed to decrease drive-alone trips of students from $44 \%$ in 1997 to $17 \%$ in 2012 . Nearly $21 \%$ students walked to campus and more than $45 \%$ of students used transit to commute to campus, largely due to a PSU policy to provide partially subsidized transit passes for the campus community (PSU, 2013).

The University of California Berkeley (UC Berkeley) is another campus that made great strides to reduce single occupancy vehicle trips. Their strategies included increasing parking fees and providing incentives to students for participating in ridesharing and using transit for their commutes. A 2012 study performed at UC Berkeley confirmed the success of those efforts. The study reported that the UC Berkeley had a $26 \%$ drive-alone rate with only $6 \%$ of students and $43.5 \%$ of faculty/staff driving alone to campus (Riggs, 2014). These rates are far lower than the $73 \%$ average drive-alone rate reported by an analysis of the 2016 American Community Survey (ACS) data performed by the Brookings Institution. The UC Berkeley study concluded that by providing transit passes, as well as incentives and price cuts on alternative modes of transportation, commuters increase the use of transit and reduce SOV trips (Riggs, 2014). Further, the study demonstrated the value of a preference survey that helps transportation officials make sustainable decisions and balance costs.

Similar benefits can be realized in Birmingham, Alabama by utilizing the UAB commuter survey findings summarized in this paper to promote strategies that reduce SOV commuting trips. This is important as UAB fares worse than peer institutions with respect to automobile dependent commuting patterns as shown in Table 5.

Table 5. Student Commuting Choices at UAB and Peer Institutions

\begin{tabular}{lccc}
\hline University & $\begin{array}{c}\text { Single Occupancy } \\
\text { Vehicle (SOV) }\end{array}$ & $\begin{array}{c}\text { Sustainable } \\
\text { Mode }\end{array}$ & $\begin{array}{c}\text { Shuttle or } \\
\text { Transit }\end{array}$ \\
\hline UAB & $82.5 \%$ & $17.5 \%$ & $1.3 \%$ \\
University of South Florida & $55.2 \%$ & $44.8 \%$ & $11.2 \%$ \\
University of Cincinnati & $38.0 \%$ & $62.0 \%$ & NA \\
University of Illinois - Chicago & $13.4 \%$ & $86.6 \%$ & $55.0 \%$ \\
\hline
\end{tabular}

The contribution of this UAB commuter survey is important for the UAB campus and the surrounding community as it is the first study of its kind documenting commuting patterns at UAB. Benchmarking current practices and 
preferences assists the University and city and regional transportation partners, to identify students transportation needs and address these needs in the nearand long-term future. Already, the recommendations provided by this study were used by the UAB Sustainability Transportation working group to formulate specific transportation sustainability promotion goals as part of the UAB 5-year strategic plan development process. As policy and infrastructure-related changes are introduced and new initiatives are implemented to reduce the very high proportion of $\mathrm{UAB}$ student commuters driving solo to $\mathrm{UAB}$, follow-up surveys are recommended to quantify changes in commuting behaviors and measure progress toward transportation sustainability goals at the UAB campus.

Another contribution of this study was adding to the limited available literature documenting university student travel behavior. The study serves as a reference for other university campuses that are interested in understanding commuting patterns of their users and undertaking design, planning, policy, education, and encouragement initiatives to serve better their current and future commuting needs.

Future work can use findings from the UAB commuter survey to represent better the travel behavior of university students in local and regional travel demand models and to improve strategic transportation planning initiatives at $\mathrm{UAB}$ and the surrounding communities. Also, a detailed cost-benefit analysis is recommended to analyze the economic impacts of active transportation, transit and ridesharing options and guide local decision makers on the implementation of solutions that have the great potential for success. Finally, the study recommends that universities should address campus transportation issues from a holistic approach and development comprehensive strategic plans that promote sustainable transportation solutions. Such solutions would, in turn, encourage social interaction, foster healthy living and active commute choices, and reduce the ecological footprint of university campuses on the adjacent local environment. In this quest, universities should work closely with local cities and neighborhoods, transportation and planning agencies, transportation and transit providers and other stakeholders to provide viable options that fulfill the students commuting needs in a responsible, safe, convenient and practical way.

\section{Acknowledgments}

This study was sponsored by the Regional Planning Commission of Greater Birmingham (RPCGB). The author would like to thank RPCGB for their support and acknowledge the valuable contributions of Dr. Ossama Ramadan and Ms. Rachael Thompson to the data processing and analysis phases of the study.

\section{References}

Barata, E., Cruz, L., and Ferreira, J. P. "Parking at the UC campus: Problems and Solutions" Cities 28, no. 5: 406-413, 2011. 
Eom, J. K., J. R. Stone and S. K. Ghosh. Daily Activity Patterns of University Students. Journal of Urban Planning and Development, Vol. 135, No. 4, 2009, pp. 141-149. Doi: 10.1061/(ASCE)UP.1943-5444.0000015.

Ma, Y. Travel Patterns of University Students in North Carolina. Master of Science Thesis, University of North Carolina at Chapel Hill, 2015.

Massachusetts Rideshare Program. Guidance on Collecting Commute Data: Census Survey, Random Sample Survey, and Direct Count Methods. Revised 2014. Available at http://www.mass.gov/eea/docs/dep/air appro vals/guiddata.pdf.

PSU-Portland State University Transportation Update 2013. Available at http://bit.ly/ 2BfnBUG.

Riggs, W., "Dealing with Parking Issues on an Urban Campus: The Case of UC Berkeley." Case Studies on Transport Policy 2:168-176, 2014.

Schroeder, B. J., C. M. Cunningham, D. J. Findley, J. E. Hummer and R. S. Foyle. Manual of Transportation Engineering Studies, 2nd Ed. Institute of Transportation Engineers, Washington, DC, 2010.

Wang, X., A. J. Khattak and S. Son. What Can Be Learned from Analyzing University Student Travel Demand? Transportation Research Record: Journal of the Transportation Research Board, Vol. 2322, 2012, pp. 129-137. Doi: 10.3141/ 2322-14. 